\title{
OPEN Understanding the role of aerobic fitness, spatial learning, and hippocampal subfields in adolescent males
}

\begin{abstract}
Sandhya Prathap ${ }^{1,2}$, Bonnie J. Nagel ${ }^{3}$ \& Megan M. Herting ${ }^{1 \bowtie}$
Physical exercise during adolescence, a critical developmental window, can facilitate neurogenesis in the dentate gyrus and astrogliogenesis in Cornu Ammonis (CA) hippocampal subfields of rats, and which have been associated with improved hippocampal dependent memory performance. Recent translational studies in humans also suggest that aerobic fitness is associated with hippocampal volume and better spatial memory during adolescence. However, associations between fitness, hippocampal subfield morphology, and learning capabilities in human adolescents remain largely unknown. Employing a translational study design in 34 adolescent males, we explored the relationship between aerobic fitness, hippocampal subfield volumes, and both spatial and verbal memory. Aerobic fitness, assessed by peak oxygen utilization on a high-intensity exercise test $\left(\mathrm{VO}_{2}\right.$ peak), was positively associated with the volumetric enlargement of the hippocampal head, and the CA1 head region specifically. Larger CA1 volumes were also associated with spatial learning on a Virtual Morris Water Maze task and verbal learning on the Rey Auditory Verbal Learning Test, but not recall memory. In line with previous animal work, the current findings lend support for the long-axis specialization of the hippocampus in the areas of exercise and learning during adolescence.
\end{abstract}

Low physical activity levels during adolescence is a growing public health concern ${ }^{1,2}$, with less than $8 \%$ of adolescents meeting the daily exercise requirements of 1 hour of physical activity ${ }^{3}$ recommended by World Health Organization and the US Department of Health ${ }^{4-6}$. Adolescence is a key transitional period of physical, emotional, and social growth ${ }^{7}$ characterized by substantial brain growth ${ }^{8-10}$. Rapid neural maturation and concomitant delayed cognitive development during this critical period of development makes this population especially sensitive to environmental and lifestyle influences, such as physical exercise.

Aerobic fitness can be defined as the body's ability or capacity to engage the respiratory and circulatory systems to deliver oxygen during an activity ${ }^{11}$. Aerobic fitness and more generally exercise is linked to improved learning and memory abilities during adolescence ${ }^{12-15}$, and may act as a protective factor against physical and mental health problems later in life ${ }^{16-18}$. Animal studies have established that voluntary exercise increases neurogenesis in the dentate gyrus $(\mathrm{DG})^{19}$. In addition, exercise has been linked to differences in cell density as determined by Nissl stain Cornu Ammonis areas CA1 and CA3 regions of the hippocampus during adolescence in juvenile male rats ${ }^{20}$. Subsequent research in male rats also suggests exercise-related astrocytic changes within the hippocampus ${ }^{21-23}$, including increases in astrocyte density and morphology in the CA1 region ${ }^{22}$. Furthermore, these exercise-induced changes occur in conjunction with enhanced hippocampal dependent memory abilities, such as spatial memory performance in the Morris Water Maze task, a powerful tool for assessing spatial mapping abilities in rodents ${ }^{19,20}$. Translating these studies to humans, our previous work has utilized peak oxygen consumption testing (i.e., $\mathrm{VO}_{2}$ peak; the gold-standard in assessing aerobic fitness), a virtual Morris Water Maze paradigm, and a cross-sectional design to establish that aerobic fitness is associated with larger hippocampal volumes and superior spatial learning abilities on a virtual Morris Water Maze in adolescent males ${ }^{24}$. Based on prior animal literature ${ }^{20,22}$, aerobic exercise is likely to have regional effects on hippocampal morphology; however, this has been understudied in an adolescent population ${ }^{14,25}$. Previous imaging techniques were initially limited to global volumetric analysis of the hippocampus, which likely masks specificity of anatomical changes within

${ }^{1}$ Department of Preventive Medicine, University of Southern California, Los Angeles, CA 90023, USA. ${ }^{2}$ Neuroscience Graduate Program, University of Southern California, Los Angeles, CA 90023, USA. ${ }^{3}$ Departments of Psychiatry and Behavioral Neuroscience, Oregon Health and Science University, Portland, OR 97239, USA. ${ }^{\square}$ email: Herting@ usc.edu 


\section{a) Virtual Morris Water Maze Video Game}

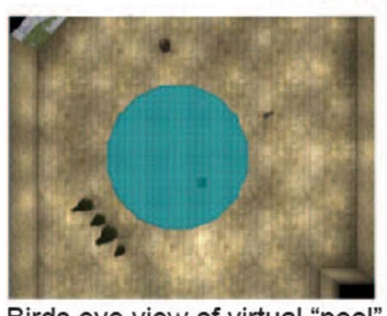

Birds eye view of virtual "pool"

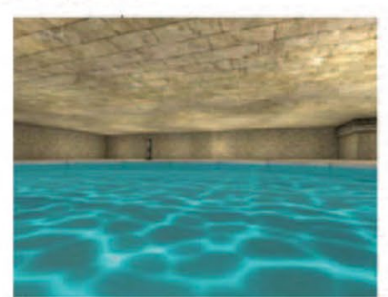

Participants view of virtual "pool" b) RAVLT Verbal Memory Test

15 word list
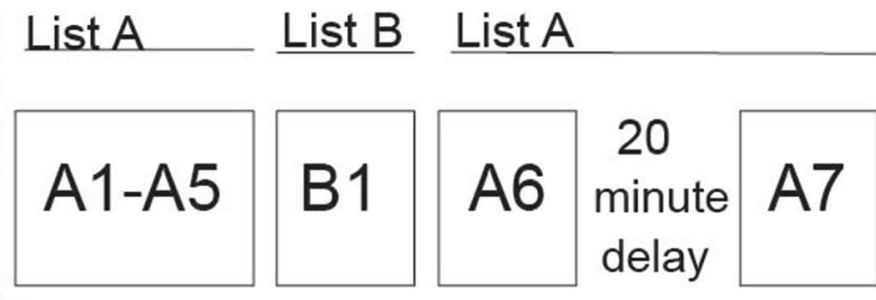

Figure 1. Spatial and verbal memory tasks. (a) Snapshots of the virtual Morris Water maze task ${ }^{57}$, including a view of the virtual pool the participant navigates in. Similar to the animal Morris Water Maze Task, participants were asked to navigate through the virtual pool using a joystick to find a hidden platform. Permission to use screenshots from this task was granted by Dr. Moffat ${ }^{57}$. (b) Sequence of the RAVLT memory task. Participants were asked to learn a list of 15 words and were later tested on number of words remembered after a delay of 20 min. Participants initially learned 15 words from list A and B, but were only tested on list A.

structurally and functionally distinct hippocampal subfields. However, recent advances utilizing histologicallyvalidated parcellations of hippocampal subfields ${ }^{26}$ allow for further exploration of regional specificity regarding the translation of exercise and learning associations with hippocampal morphology from animal to human studies. Cross-species comparisons of hippocampal subfields between rats and humans are vital to better inform our understanding of both macro and micro scale hippocampal plasticity induced by exercise, and whether structural morphology relates to spatial learning and memory abilities during adolescence.

Cross-sectional studies in children ${ }^{27,28}$, adolescents ${ }^{24}$, and older adults ${ }^{29}$ reveal that higher fitness levels are associated with larger hippocampal volumes and superior cognitive performance. Human structural and functional magnetic resonance imaging (MRI) research over the past decade suggests that exercise and various memory abilities may differentially affect specific subfields within the hippocampus. Randomized control trials (RCTs) in both young and older adults have also localized aerobic exercise training improvements with the enlargement of cortical grey matter ${ }^{30-32}$, changes in neurovasculature ${ }^{33,34}$, resting state functional connectivity ${ }^{35}$, and myelination ${ }^{31}$ within the anterior portion of the hippocampus. The anterior hippocampus (ventral hippocampus in rats) is a neurogenic zone ${ }^{36-38}$. Various aspects of spatial navigation (e.g. encoding vs. retrieval) are also thought to be functionally differentiated along the longitudinal axis of the hippocampus ${ }^{39,40}$. Other types of memory such as verbal learning and delay recall, a type of episodic memory, is also thought to involve the anterior hippocampus ${ }^{41}$. Within the anterior region, a few RCTs have further localized exercise-induced sMRI growth and increased cerebral blood volume to the DG region ${ }^{32,34}$ (i.e. the site of neurogenesis which creates adult granule cells ${ }^{36,37}$ ) and $\mathrm{CA}^{32}$. On the other hand, others have only observed sMRI increases in the CA1 subfield following a RCT intervention ${ }^{42}$. Across the hippocampal longitudinal axis, the DG and CA regions are both crucial for spatial navigation ${ }^{43}$; however, the DG is responsible for pattern separation ${ }^{44,45}$; CA3 for pattern completion $^{46,47}$; and CA1 is more generally involved with encoding ${ }^{48,49}$. While these MRI studies suggest that the DG, CA1, and CA3 subfields are influenced by exercise, there is a lack of consistency with respect to MRI resolution and hippocampal segmentation methods, and age group-which primarily focuses on older adult populations. Moreover, few studies have looked to examine how exercise and learning behaviors both map to hippocampal subfields during adolescent development.

The neuroprotective effects of exercise during the period of adolescence has been largely understudied ${ }^{14,25}$. Adolescence presents a unique phase of development in which neural circuitry and cognitive functions have not reached peak development. SMRI studies reveal that overall hippocampal volume ${ }^{50,51}$ and hippocampal subfield volumes follow a protracted developmental trajectory; peaking during early adolescence ${ }^{52}$. Furthermore, exercise may differentially modify hippocampal plasticity during the ongoing development of these systems during adolescence, as more robust hippocampal neurogenesis is observed in young adult rats compared to older adult rats $^{53}$. Altogether, exercise may hold great promise to enhance learning and memory capabilities during the teenage years-which is a critical period for academic achievement ${ }^{12,13}$. Identifying subfield structural correlates associated with aerobic fitness, spatial, and verbal memory domains during this developmental period is necessary to localize exercise induced hippocampal plasticity within subfields.

Employing a translational approach, the aim of the present study was to determine if aerobic fitness and virtual Morris Water Maze Task performance (vMWT) (Fig. 1a) are associated with specific T1-weighted MRI structural subfield volumes of the hippocampus in 34 adolescent males. Importantly, all adolescents were of healthy (i.e. non-obese) weight status; reducing body weight effects which can possibly confound studies trying to capture 'fitness' effects ${ }^{14}$. Linear mixed effect models were used to compute associations between aerobic fitness, spatial learning and memory performance, and hippocampal subfields for each hemisphere. Finally, associations between a verbal learning and memory task (i.e. Rey Auditory Verbal Learning Test (RAVLT); (Fig. 1b) and hippocampal subfields were also assessed to probe potential specificity between the spatial and verbal learning and memory domains. Based on findings from the animal literature ${ }^{20,22}$, we predicted that higher aerobic fitness levels would be associated with larger subfield volumes in the head region, specifically within the DG, CA1, and CA3 


\begin{tabular}{|c|c|c|c|}
\hline & Mean & sd & $\mathbf{n}$ \\
\hline \multicolumn{4}{|l|}{ Demographics } \\
\hline Age & 16.42 & 0.82 & 34 \\
\hline PDS & 3.19 & 0.39 & 34 \\
\hline IQ & 117.56 & 9.62 & 34 \\
\hline SES & 22.41 & 10.75 & 34 \\
\hline Household income & 128.24 & 73.01 & 33 \\
\hline BMI & 22 & 3.38 & 34 \\
\hline $\mathrm{VO}_{2}$ peak $(\mathrm{ml} / \mathrm{kg} / \mathrm{min})$ & 63.76 & 11.93 & 34 \\
\hline LBM based $\mathrm{VO}_{2}$ peak $(\mathrm{ml} / \mathrm{kg} \mathrm{LBM} / \mathrm{min})$ & 72.35 & 10.46 & 34 \\
\hline vMWT Spatial learning & 0.35 & 0.22 & 30 \\
\hline vMWT Spatial delay recall & 2 & 1.49 & 30 \\
\hline RAVLT Verbal learning (z score) & 1.73 & 0.82 & 33 \\
\hline RAVLT Verbal delay recall & -0.39 & 1.58 & 33 \\
\hline \multicolumn{4}{|l|}{ MRI volumes* $\left(\mathrm{mm}^{3}\right)$} \\
\hline Hippocampus & 4034.51 & 472.06 & 34 \\
\hline Hippocampal head & 2095.40 & 245.22 & 34 \\
\hline Hippocampal body & 1388.87 & 152.12 & 34 \\
\hline Hippocampal tail & 637.56 & 69.81 & 34 \\
\hline CA1 head & 635.83 & 77 & 34 \\
\hline CA3 head & 162.17 & 25.63 & 34 \\
\hline CA4 head & 162.88 & 22.61 & 34 \\
\hline DG head & 197.01 & 28.18 & 34 \\
\hline Presubiculum head & 165.84 & 21.53 & 34 \\
\hline Subiculum head & 213.91 & 30.92 & 34 \\
\hline CA1 body & 145.75 & 27.64 & 34 \\
\hline CA3 body & 99.15 & 19.46 & 34 \\
\hline CA4 body & 139.94 & 18.61 & 34 \\
\hline DG body & 158.66 & 21.31 & 34 \\
\hline Presubiculum body & 193.14 & 24.59 & 34 \\
\hline Subiculum body & 281.94 & 30.20 & 34 \\
\hline Parasubiculum & 81.41 & 13.33 & 34 \\
\hline
\end{tabular}

Table 1. Participant demographics. $s d$ standard deviation, IQ Wechsler Abbreviated Scale of Intelligence, SES Hollingshead Index of Social position, $v M W T$ Virtual Morris Water Maze Task, RAVLT Rey Auditory Verbal Learning Test, $C A$ cornu ammus, $D G$ dentate gyrus. ${ }^{\star}$ Left and right region of each subfield are combined.

head subfields. Given previous human hippocampal subfield studies in the domains of spatial ${ }^{49,54}$ and episodic verbal memory ${ }^{41}$, we also expected spatial learning to be associated with larger subfield volumes in the DG and CA1 subregion, and both verbal learning and memory to be associated with subfield volumes in the head region.

\section{Results}

Aerobic fitness is positively related to CA1 head subfield. Participants completed the gold-standard Bruce protocol test ${ }^{55}$ for quantifying aerobic fitness by peak oxygen consumption $\left(\mathrm{VO}_{2}\right.$ peak, adjusted for lean body mass ( $\mathrm{ml} / \mathrm{kg} \mathrm{LBM} / \mathrm{min}))^{56}$ and structural 3T T1-weighted images (Table 1). Based on the literature, an a priori model building strategy was used to examine the association between $\mathrm{VO}_{2}$ peak and hippocampal subfields along the anterior-posterior axis of the hippocampus (Fig. 2a). First, we examined a potential interaction between $\mathrm{VO}_{2}$ peak $(\mathrm{ml} / \mathrm{kg} \mathrm{LBM} / \mathrm{min})$ and regional differences in volume along the longitudinal axis, including the head, body, and tail of the hippocampus (Fig. 1a). Hippocampus volumes significantly differed along the longitudinal axis in relation to aerobic fitness $\left(\mathrm{F}(2,165)=5.78, p=0.004, \mathrm{R}^{2}\right.$ model $\left.=0.96\right)$. Follow-up analyses revealed a significant association between aerobic fitness and hippocampal volume in the head, whereas this association was not significant in the body or tail (Table 2). Next, we performed follow-up analyses to probe if aerobic fitness related to volumetric differences of the subfields within the head region of the longitudinal axis of the hippocampus (Fig. 2b). Given previous findings from animal literature ${ }^{20,22}$, we examined the CA1, CA3, $\mathrm{CA} 4$, and DG subfields. Scatter plot of $\mathrm{VO}_{2}$ peak with the hippocampus head, as well as each of the head subfield volumes are presented in Supplementary Fig. S2. In final models taking into consideration the shared variance of subfield volumes between and within hemispheres for any given individual, and adjusting for covariates, significant differences were observed with aerobic fitness and distinct subfield volumes $(\mathrm{F}(3,231)=12.58, p=0.001$, $\mathrm{R}^{2}$ model $=0.98$, which was driven by a positive association between aerobic fitness and the CA1 head region 


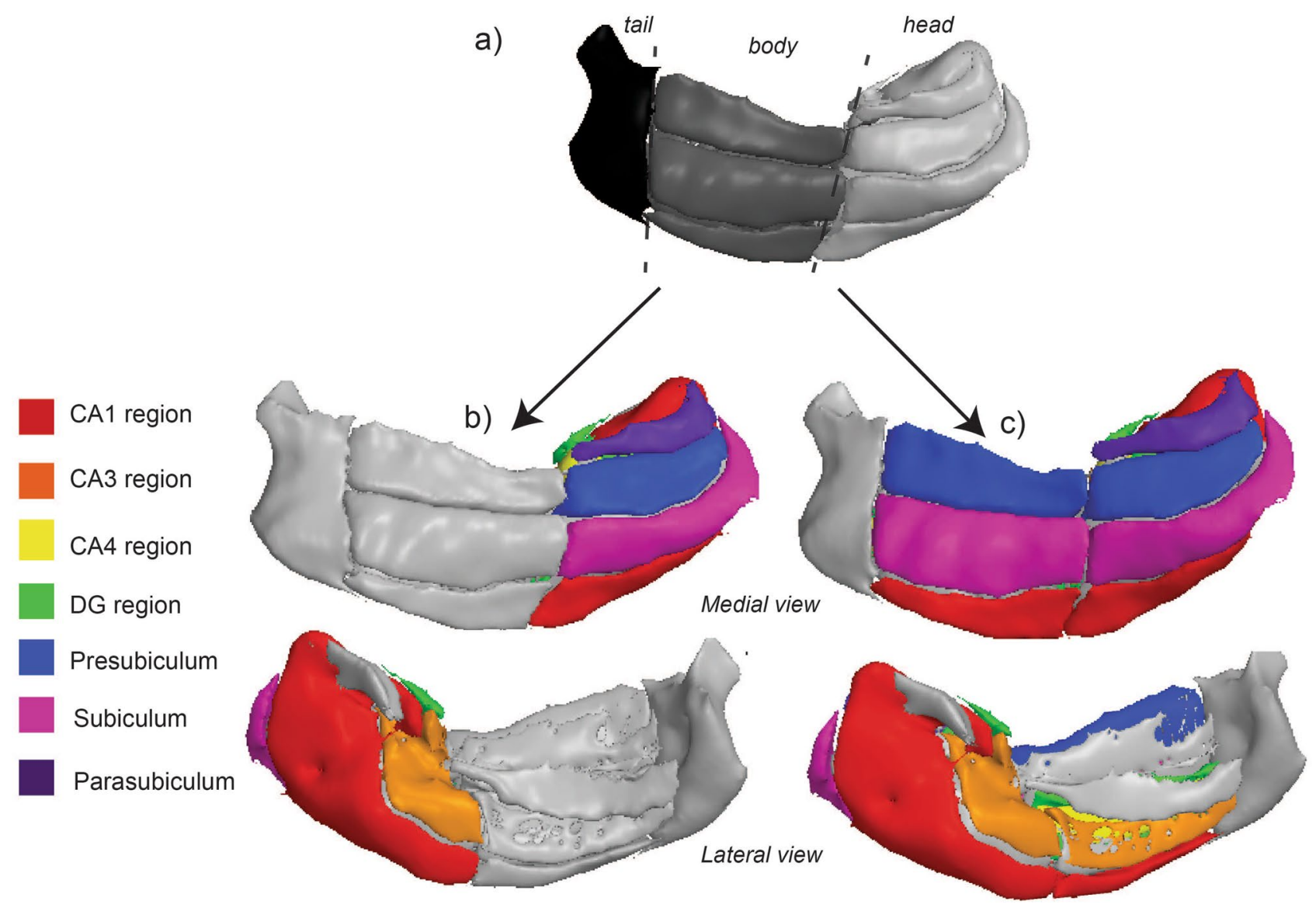

Figure 2. Visual representation of anterior to posterior longitudinal axis and subfield model building strategy. (a) We first examined a potential interaction between the independent variables (IVs) of interest and regional differences in volume along the longitudinal axis (head, body, tail ROIs) of the hippocampus using a linear mixed model analysis. (b) If interaction of the initial model was significant, follow-up analyses examined volume differences of the subfields of interest (i.e. CA1, CA3, CA4, DG, presubiculum, subiculum, and parasubiculum) within the longitudinal axis region identified by the initial model. A priori animal and human literature determined the specific subfields that were in included in the analysis for each IV of interest. (c) If no differences were observed in volume along the longitudinal axis (i.e. interaction term for the longitudinal axis was not significant), then the subfields of interest (i.e. CA1, CA3, CA4, DG, presubiculum, subiculum, and parasubiculum) were examined for the entire length of the hippocampal formation. Hippocampal images were created using Quantitative Imaging Toolkit (QIT) ${ }^{143}$.

\begin{tabular}{|l|l|l|l|l|l|l|}
\hline VO $_{2}$ peak & df & Beta & se & t-stat & $\boldsymbol{p}$ value & $\mathbf{R}^{2}$ partial \\
\hline Longitudinal axis volumes \\
\hline Head $^{* *}$ & 30 & 6.95 & 2.34 & 2.97 & $\mathbf{0 . 0 0 6}$ & 0.04 \\
\hline Body & 30 & 2.45 & 2.34 & 1.05 & 0.31 & 0.002 \\
\hline Tail & 30 & 1.32 & 2.34 & 0.56 & 0.58 & 0.005 \\
\hline Head subfield volumes \\
\hline CA1 $^{* *}$ & 30 & 2.56 & 0.6 & 4.26 & $\mathbf{0 . 0 0 0 2}$ & 0.2 \\
\hline CA3 $^{*}$ & 30 & 0.11 & 0.6 & 0.18 & 0.86 & 0.168 \\
\hline CA4 & 30 & 0.33 & 0.6 & 0.56 & 0.56 & 0.088 \\
\hline DG & 30 & 0.49 & 0.6 & 0.082 & 0.42 & 0.075 \\
\hline
\end{tabular}

Table 2. Association between $\mathrm{VO}_{2}$ peak and hippocampal volumes. Table of the associations between $\mathrm{VO}_{2}$ peak and hippocampal subfields using linear mixed effect models. ${ }^{* *} p<0.007$. Bold text reflects significant $p$-values after Bonferroni correction. 
(Table 2, Fig. 3). The Shapiro-Wilks test confirmed that the relevant variables did not violate assumptions of normality (see Supplementary Table S1).

Spatial learning on the Virtual Morris Water Maze Task relates to CA1 subfield volume. In order to improve translation of findings between animal and human studies, spatial learning and memory were assessed using a computerized virtual Morris Water Maze task (vMWT) aimed to mirror the animal version of the $\operatorname{task}^{57}$ (Fig. 1a). Participants used a joystick to "swim" and find a hidden platform in a computerized environment of a pool set inside a larger room. Within the pool there was a hidden platform, and the task required participants to learn the pool environment, using a set of spatial cues, to find the hidden platform as fast as possible. When the participant swam over the hidden platform, it emerged from the water and hoisted the participant out of the pool for 10 seconds (s) indicating that a trial was completed. Following a practice trial, the individual completed 6 learning trials. During the learning trials, participants were told that the hidden platform would remain in the same new position for all of the trials. While the participant searched for and found the hidden platform, the computer recorded the $(\mathrm{x}, \mathrm{y})$ coordinate position approximately every $0.02 \mathrm{~s}$. Using this method, the computer calculated the total distance traveled in each quadrant of the pool, including the quadrant that the hidden platform was located in-known as the target quadrant. Percent distance traveled (i.e. total distance traveled in the target quadrant divided by the total distance traveled across all quadrants) was calculated for each of the 6 learning trials. The amount of learning that occurred over the 6 trials was captured by improvements in the percent of time, or delta $(\delta)$, from the first to last learning trial $(\delta=$ percent distance trial 6 - percent distance trial 1). We found that spatial learning on the vMWT was not associated with volumetric differences along the longitudinal axis (i.e. head, body, and tail segments; $\mathrm{F}(2,145)=2.13, p=0.13, \mathrm{R}^{2}$ model $=0.96$ ). Animal studies suggest that hippocampal place cells, located within the subiculum-related and CA subfields, are integral for spatial memory formation ${ }^{58}$. Based on this rationale, we then further examined whether spatial learning related to volumes within the subfields of the CA1, CA3, CA4, DG, parasubiculum, presubiculum, and subiculum (Fig. 2c). The association between spatial learning and volumes across these 7 subfields were significantly different $\left(\mathrm{F}(6,377)=3.21, p=0.005, \mathrm{R}^{2}\right.$ model $\left.=0.97\right)$. Larger CA1 volumes were found to relate to better spatial learning across the 6 trials of the task (Table 3, Fig. 3b).

30 minutes after the completion of the learning trials on the vMWT, participants were asked to complete a spatial delay recall trial. The spatial delay recall trial was identical to the learning trials, but the hidden platform was removed. This was done to assess whether the participant remembered the location of the hidden platform that was identified during the previous learning trials. Spatial delay recall was calculated as the percent distance traveled in the target quadrant within the first 30s of the trial. Spatial delay recall memory on this task was not associated with volumes along the longitudinal axis of the hippocampus $\left(\mathrm{F}(2,145)=1.31, p=0.28, \mathrm{R}^{2}\right.$ model $=0.96)$ or any subfield volumes $\left(\mathrm{F}(6,377)=0.67, p=0.69, \mathrm{R}^{2}\right.$ model $\left.=0.97\right)$.

Since we had previously shown that aerobic fitness and spatial learning on this task was significant in this sample; $\left(\text { beta }=0.012, p=0.001, \mathrm{R}^{2} \text { model }=0.34\right)^{24}$, a four-step mediation analysis model outlined by Baron and Kinney ${ }^{59}$ was performed to test whether hippocampal subfield volume CA1 would mediate the relationship between aerobic fitness and spatial learning. For this analysis simple linear regression models were utilized, and covariates total ICV and pubertal development were included. Left and right CA1 head and body volumes were summed, and then left and right hemisphere volumes were averaged to create overall CA1 volumes. We found a significant relationship between aerobic fitness and the CA1 subfield ( beta $=2.96, p<0.04, \mathrm{R}^{2}$ model $=0.38$ ) indicating a significant relationship between the IV and mediator of interest. Given that (1) aerobic fitness predicts both learning on the vMWT, as well as CA1 subfield volumes, and (2) CA1 subfield volumes predicts spatial learning, multiple linear regressions were performed to determine if hippocampal volume predicts spatial learning, while controlling for aerobic fitness. The relationship between the CA1 subfield volume (outcome) and spatial learning (the mediator) (while controlling for the IV of $\mathrm{VO}_{2}$ peak) was not significant (beta $=0.0003$, $p=0.45, \mathrm{R}^{2}$ model $=0.38$ ). Thus, the CA1 subfield as a potential mediator does not relate to spatial learning (i.e. the outcome of interest). Since the mediator does not relate to the outcome, conditions were not met to test CA1 subfield volume as a mediator of the relationship between aerobic fitness and spatial learning in the current study. Rather, these findings suggest that the relationship seen between the CA1 subfield and spatial learning is largely driven by individual associations of CA1 subfield volume and spatial learning with aerobic fitness.

Verbal learning is positively related to CA1 head subfield. Verbal learning was measured using the RAVLT test (Fig. 1b), and a higher verbal learning score reflected a greater number of words learned over 5 learning trials. Verbal learning was found to associate with hippocampus volumes differentially along the longitudinal axis $\left(\mathrm{F}(2,160)=9.0, p=0.001, \mathrm{R}^{2}\right.$ model $\left.=0.96\right)$, with larger volumes of the head specifically associated with better verbal learning (Table 3). Again, we performed follow-up analyses to probe if verbal learning related to volumetric differences of the subfields within the head region of the longitudinal axis of the hippocampus. Since a limited number of studies have examined verbal learning with respect to hippocampal subfields ${ }^{41,49}$, all of the head-related CA, DG, and subiculum subfields were included in the follow up analysis. Results showed volumetric differences of the head region in the association with verbal learning $\left(\mathrm{F}(5,352)=3.16, p=0.009, \mathrm{R}^{2}\right.$ model $=0.98$ ), with larger CA1 head volumes associated with learning more words over the 5 learning trials (Table 3, Fig. 3). Performance on the verbal delay recall memory portion of the RAVLT, which asks participants to list all the words they can remember after 20 minutes, was not found to associate with volumes along the longitudinal axis of the hippocampus $\left(\mathrm{F}(2,160)=2.51, p=0.09, \mathrm{R}^{2}\right.$ model $\left.=0.96\right)$ or any subfield volumes $\left(\mathrm{F}(6,416)=1.15, p=0.34, \mathrm{R}^{2}\right.$ model $\left.=0.97\right)$. In order to test for mediation effects between aerobic fitness, CA1 head volume, and verbal learning, follow-up regression analyses were first performed to determine the rela- 


\section{a) Aerobic fitness}

\section{CA 1 head subfield}

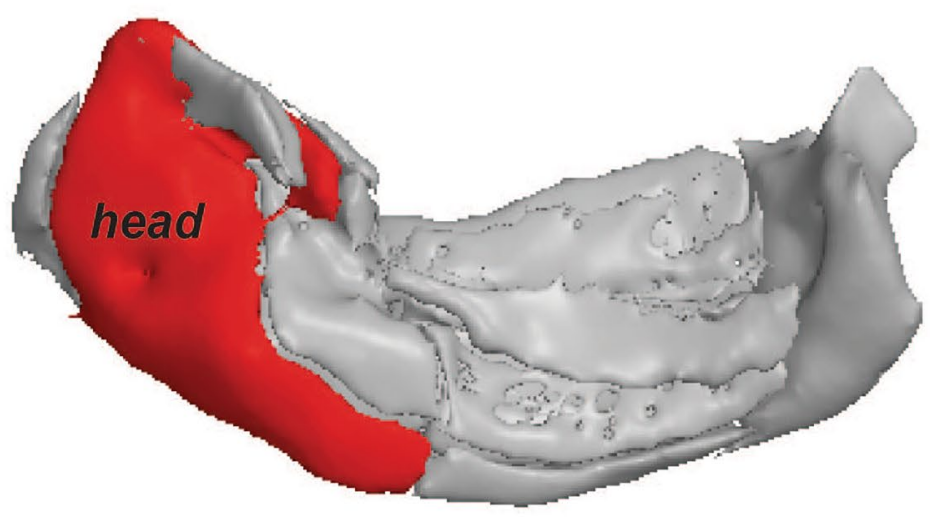

\section{b) Spatial learning}

\section{CA 1 head and body subfield}

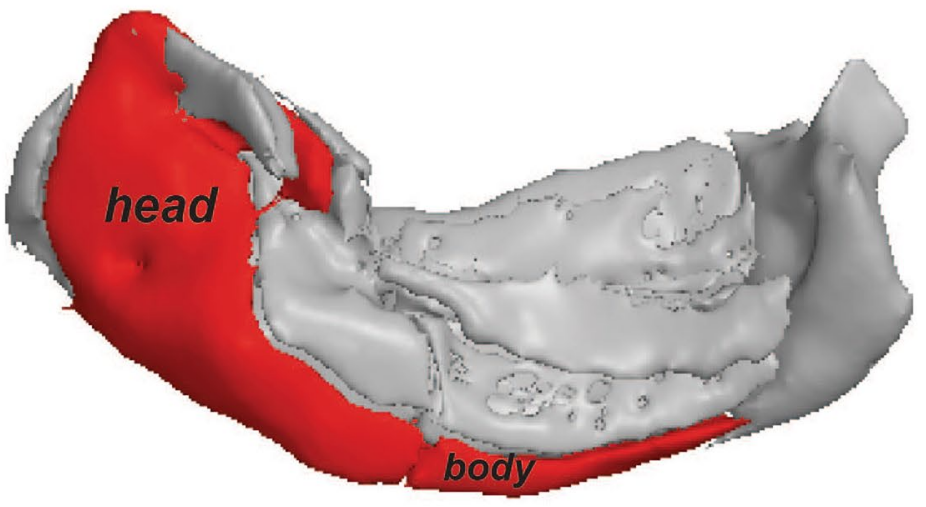

\section{c) Verbal learning}

\section{CA 1 head subfield}

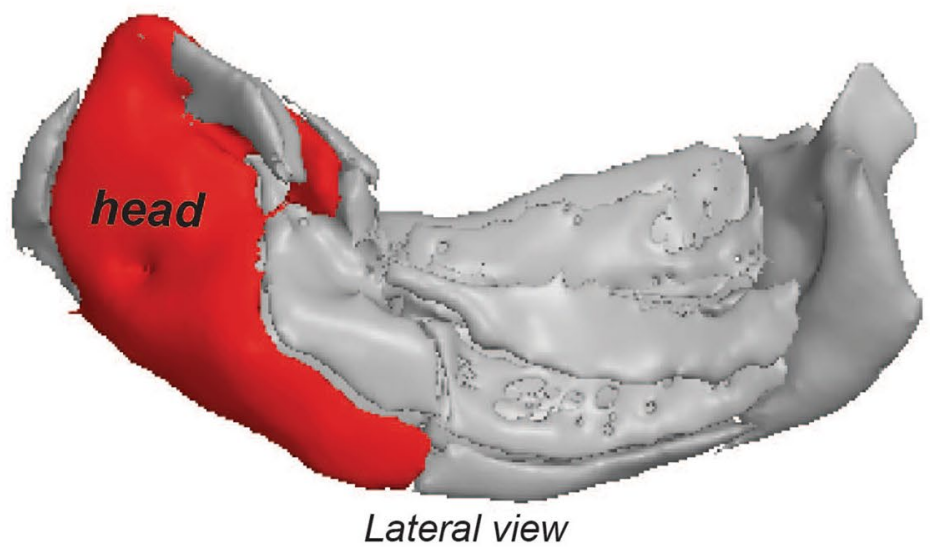

Figure 3. Hippocampal subfields associated with exercise and cognitive domains. A 3-D representation of the positive associations between IV variables of interest: (a) aerobic fitness, (b) spatial learning, and (c) verbal learning with CA1 subfields. Positive associations correspond to larger volumes within the CA1 subfield. Hippocampal images were created using Quantitative Imaging Toolkit (QIT) ${ }^{143}$. 


\begin{tabular}{|c|c|c|c|c|c|c|}
\hline & df & Beta & se & t-stat & $p$ value & $\mathbf{R}^{2}$ partial \\
\hline \multicolumn{7}{|l|}{ Spatial learning } \\
\hline \multicolumn{7}{|l|}{ Subfield volumes } \\
\hline $\mathrm{CA1}^{\star *}$ & 26 & 122.6 & 37.21 & 3.29 & 0.003 & 0.07 \\
\hline CA3 & 26 & 20.18 & 37.21 & 0.54 & 0.6 & 0.03 \\
\hline CA4 & 26 & 24.43 & 37.21 & 0.66 & 0.52 & 0.03 \\
\hline DG & 26 & 31.27 & 37.21 & 0.84 & 0.41 & 0.03 \\
\hline Parasubiculum & 26 & 8.52 & 37.21 & 0.23 & 0.83 & 0.04 \\
\hline Presubiculum & 26 & 26.24 & 37.21 & 0.71 & 0.49 & 0.03 \\
\hline Subiculum & 26 & 47.61 & 37.21 & 1.28 & 0.22 & 0.02 \\
\hline \multicolumn{7}{|l|}{ Verbal learning } \\
\hline \multicolumn{7}{|c|}{ Longitudinal axis volumes } \\
\hline Head $^{* *}$ & 29 & 101.28 & 28.38 & 3.57 & 0.002 & 0.07 \\
\hline Body & 29 & 35.59 & 28.38 & 1.25 & 0.22 & 0.002 \\
\hline Tail & 29 & 9.47 & 28.38 & 0.33 & 0.75 & 0.006 \\
\hline \multicolumn{7}{|c|}{ Head subfield volumes } \\
\hline $\mathrm{CA}^{* *}$ & 29 & 27.39 & 6.47 & 4.23 & 0.001 & 0.11 \\
\hline CA3 & 29 & 9.67 & 6.47 & 1.49 & 0.15 & 0.03 \\
\hline CA4 & 29 & 9 & 6.47 & 1.39 & 0.18 & 0.03 \\
\hline DG & 29 & 11.79 & 6.47 & 1.82 & 0.08 & 0.02 \\
\hline Presubiculum & 29 & 7.95 & 6.47 & 1.23 & 0.23 & 0.03 \\
\hline Subiculum & 29 & 10.97 & 6.47 & 1.69 & 0.11 & 0.02 \\
\hline
\end{tabular}

Table 3. Association between spatial and verbal learning on hippocampal volumes. Table of the associations between spatial and verbal learning and hippocampal subfields using linear mixed effect models. ${ }^{* *} p<0.007$. Bold text reflects significant $p$-values after Bonferroni correction.

tionship between aerobic fitness and verbal learning. There was not a significant association between the two $(p=0.618)$. Therefore associations did not meet criteria for directly testing a mediation analysis ${ }^{59}$.

\section{Discussion}

While studies have demonstrated an association between total hippocampal volumes and aerobic fitness in children and adolescence, this study utilized an advanced hippocampal subfield segmentation technique ${ }^{26}$ to better translate known aerobic exercise and learning associations with hippocampal substructures from animal studies to humans during adolescence. Aerobic fitness, assessed by $\mathrm{VO}_{2}$ peak, and verbal learning were found to positively relate to larger hippocampal head volumes, and especially in the CA1 head region. Alternatively, larger CA1 spanning both the head and body of the hippocampus was found to relate to better spatial learning.

In line with our hypothesis, our results revealed that aerobic fitness levels are associated with a larger hippocampal head in adolescent males. Histological evidence dating back to the late $1500 \mathrm{~s}$ supports the tripartite division of the hippocampus along the longitudinal axis ${ }^{60}$. Each division displays divergent structural, functional, and gene expression properties ${ }^{39}$. A handful of exercise-based RCT imaging studies in young adult and older populations have identified volumetric increases in both the anterior and head region of the hippocampus associated with fitness improvements ${ }^{30-32}$. Moreover, these results are also in line with rodent exercise studies observing plasticity differences in the ventral hippocampal (anterior equivalent) ${ }^{61}$. The anterior region of the hippocampus displays a high degree of plasticity; it is more suspectable to various environmental and biological processes, such as stress, depression, and aging related neurodegeneration ${ }^{62-64}$. Furthermore, neurogenesis in this region is more easily altered via pharmacological agents ${ }^{62}$. Structurally, the ventral hippocampus uniquely projects to regions associated with cognitive control and emotion regulation (prefrontal cortex, amygdala, nucleus accumbens, and hypothalamic-pituitary-adrenal axis $)^{65}$. Subfields within the anterior hippocampus display less gyrification $^{66}$ and have limited cross-sectional and longitudinal anatomical connectivity to other regions of the hippocampus, as compared to the posterior hippocampus ${ }^{40}$. The limited connectivity within the head region is present in non-human primates, but not observed in rat hippocampal homologue, and may be a signature of higher order species ${ }^{67}$. Interestingly, while some trend level associations were seen between aerobic fitness and volumes of other head subfields, after adjusting for covariates in our final models, we found the association with aerobic fitness was most apparent in the CA1 region within the hippocampal head region. Cellular cytoarchitecture within subfields of the head region display unique morphological properties such as more densely packed pyramidal cell bodies in the CA1 head, and the DG head serving as the primary neurogenic zone, with a larger pool of mature adult granule cells, and a small pool of immature granule neurons ${ }^{68}$. Associations between aerobic fitness and CA1 head volume in the current study are similar to two recent RCT studies which have also localized training induced volumetric increases in gray matter to the enlargement of the CA1 subfield after 12 weeks of aerobic training in young adults ${ }^{42}$, and attenuated CA1 volume atrophy 12 months after cessation of 6 months of resistance training in elderly ${ }^{69}$. The CA1 may play an important role in supplying neurogenic substrates 
(e.g., glutamate, neurotrophins) to immature granule cells ${ }^{70}$, as the CA1 subfield has heightened upregulation of BDNF, TrkB, and c-fos receptor expression during exercise induced neurogensis ${ }^{71-74}$. Moreover, the current volumetric findings in the CA1 may also be reflective of astrogliogenesis, as physical exercise has been shown to increase astrocyte density as well as morphology in the CA1 region in rodents ${ }^{22}$. While clinical intervention and experimental animal studies provide insight to the neuroplastic effects of exercise over a specific training period, the results of this study indicate that an individual's overall aerobic fitness may also influence subfieldspecific volumes. In addition, similar results between previous studies in young and elderly adults $\mathrm{s}^{30-34,42}$ and our current findings in an adolescent sample suggest that the localization of exercise-related volumes in the head of the hippocampus may be ubiquitous across the lifespan.

In the current study, spatial and verbal learning performance were also found to be associated with CA1 volumes. Previous literature on the localization of spatial and verbal memory along the longitudinal axis of the hippocampus in humans is mixed. Volumetric and functional studies present discrepant evidence in support of spatial memory localized to both the posterior (body and tail) $)^{75,76}$ and anterior (head) hippocampus ${ }^{77,78}$. Our findings suggest that the CA1 region may be important for spatial learning particularly, rather than a specific anterior-posterior division of the hippocampus. The association of larger CA1 volumes and learning on the Morris Water Maze task are in agreement with a recent human lesion study from Bartsch and colleagues ${ }^{49}$. In this study, 14 transient global amnesia patients with focal lesions spanning the entire CA1 region of the hippocampus were found to have significant deficits in spatial learning on a similar virtual Morris Water Maze task, where spatial learning was also defined as the distance traveled across quadrants over a period of time ${ }^{49}$. Similarly, another virtual navigation study associated spatial learning, as defined as passive observation during a navigation task, with fMRI activation of the CA1 region ${ }^{54}$. These results from human studies suggest a role of CA1 in spatial learning, and are further supported by animal experiments which have established that CA1 neurons within the hippocampus are critically involved in both real and virtual world spatial navigation ${ }^{79-81}$. Interestingly, we also found that verbal learning, a type of episodic memory, was found to be positively associated with the volume of the head of the CA1 region. Associations between verbal learning and the head of the hippocampus have been noted in studies of adults. For example, one study in older adults found associations between verbal learning, also assessed by the RAVLT, and larger volumes within in the anterior hippocampus ${ }^{41}$. Functional imaging studies have found that verbal encoding is associated with increased activation in the anterior hippocampus ${ }^{82}$, and specifically the head region of the hippocampus during encoding of verbal stimuli compared with item stimuli ${ }^{83}$. Lastly, patients with focal lesions to the CA1 region (along the head and body), have shown deficits on RAVLT learning ${ }^{49}$. Taken together, these studies provide additional support for the importance of the CA1 in spatial and verbal learning in adolescents as seen in the current study.

While we did observe trend-level associations between aerobic fitness and the right DG and CA4 subfields within the hippocampal head, these were no longer apparent after adjusting for covariates. Exercise induced neurogenesis within the DG in adolescent rat models specifically improves pattern separation abilities ${ }^{84}$, and ultimately contributes to superior spatial navigation abilities. Thus, it was surprising that the DG subfield volumes were not significantly associated with either aerobic fitness or spatial navigation abilities. It is very likely that aerobic exercise relates to cellular processes that may be less sensitive to detection via sMRI and/or lead to smaller effect sizes requiring larger sample sizes to detect. For example, while neurogenesis creates new granule cells, these new cells represent a very small number of the total cells within the DG ${ }^{71}$, and may not be detectable by utilizing sMRI. Nonetheless, the association between aerobic fitness and CA1 volumes detected in our sample may also be reflective of a potentially unique developmental profile of this subfield during adolescence. In a recent longitudinal sMRI study, the CA3, CA4, and DG were found to show small, steady decreases in volume from childhood through mid-adulthood ${ }^{85}$. The CA1, however, showed a quadratic pattern of development, with continued growth seen throughout late adolescence ${ }^{85}$. Regional specificity in the development of hippocampal subfield volumes may suggest that the CA1 is still undergoing macro-structural changes during adolescence, which may render it more susceptible to changes in neuroplasticity related to physical exercise that are observable by sMRI. In fact, while the DG is thought of as unique given its prolonged plasticity during adulthood; widespread plasticity is a hallmark of the adolescent brain ${ }^{9,86}$. In addition, previous human MRI studies that have observed both exercise and spatial memory induced changes in the DG focused on adult populations ${ }^{32,34}$. It is feasible that exercise may have larger effects in the DG in adulthood, whereas aerobic exercise may exert its effects on other hippocampal regions, such as the CA1, during this critical period of development. Given that gray matter differences across adolescence may result from a number of biological changes, including neuronal bodies, neuropil, glial cells, and capillaries-all of which may vary across hippocampal subfields and respond differentially to aerobic exercise-volumetric differences in relation to aerobic fitness in this current cross-sectional study require further investigation. For example, glial cells far outnumber neurons by a ratio of 50 to $1^{87}$, and exercise has been shown to increase cell density ${ }^{22}$ as well as remodel the morphology of astrocytes (i.e. a subclass of glial cells) within the medial temporal lobe in male rats ${ }^{22,23}$. Furthermore, beyond neurogenesis and neuropil, aerobic exercise may lead to neurovasculature changes that could contribute to larger gray matter volumes, as a recent exercise training study showed marginal associations of anterior hippocampal cerebral blood flow (CBF) with exercise in children ${ }^{88}$, and an intervention study in older adults showed that volumetric enlargement of the head region were accompanied by increases in CBF to the hippocampus ${ }^{33}$. Thus, additional longitudinal fitness and aerobic exercise intervention studies are needed in adolescent populations to test the plausible idea that the prolonged maturation of the CA1 region may make it more sensitive to the impact of exercise across adolescence. These future imaging studies should also employ a combination of structural morphometry, arterial spin labeling, and microstructural analyses, which may help to elucidate both macro and microstructural differences associated with exercise and learning ability.

Strengths and weaknesses of the study should be noted. First, the study design employed a spatial navigation memory task analogous to the rodent equivalent of the Morris Water Maze task, allowing for improved 
translation between human and animal studies. All youth were also of healthy weight, which is important given previous studies in children and adolescents have been unable to disentangle potential differences in the association between aerobic fitness and brain structure without the potential confounding factor of overweight individuals in the lesser fit groups ${ }^{14,27}$. In addition, the current study used methods to estimate subfield volumes in humans that are more likely to mirror subregional specificity delineations in animal models. However, it should be noted that methodological challenges inherent to hippocampal segmentation methods make it rather difficult to accurately demarcate the CA4 and DG regions, as the CA4 region includes the molecular-layer of the DG ${ }^{26}$. In addition, the CA3-4, DG, and head region delineation can be impacted by scan resolution and segmentation software $^{26}$, and brain volumetric measurements can vary as a function of the age of the study population ${ }^{89}$. Thus, results of the current study should be treated as preliminary and interpreted with caution until replicated using higher resolution scan data. Additional limitations include that this study was correlational in nature and was conducted in a small sample of male participants recruited from the Pacific Northwest region of the United States. We chose to focus on males in the current study design to reduce variability given the notable sex differences that have been noted to impact the primary measurements of our study. Half of the male participants in our current study were also athletes, with $47 \%$ of the sample having $\mathrm{VO}_{2}$ peak $(\mathrm{ml} / \mathrm{kg} / \mathrm{min})$ values falling above the 95th percentile based on their age and $\mathrm{sex}^{90}$. Thus, the current findings may not be generalizable to the general adolescent male population across the U.S. More research is needed to explore similarities and/or differences in larger, diverse samples including both sexes and adextrals. Furthermore, preliminary animal studies show that the neuroprotective effects of exercise during the juvenile period (e.g., cell proliferation number, dendritic arborization, BNDF and mTOR protein expression) are maintained after adolescence and throughout a sedentary adulthood $^{91}$, suggesting that the impact of exercise during teenage years may have both unique and long-lasting protective effects well into adulthood. Thus, longitudinal and intervention studies are needed to more fully characterized how aerobic fitness may impact the developing brain throughout adolescence into adulthood.

In conclusion, the present study suggests CA1 subfield volume relates to aerobic fitness and spatial and verbal domains of learning performance during adolescence. The results shed light on how parallel animal and human studies may ultimately help to improve our understanding as to how exercise may relate to macroscale changes of the hippocampus. Further collaborations between experimental cellular neuroscience and human imaging studies are needed to better understand the neuroanatomical underpinnings of macrostructural changes at the voxel level.

\section{Methods}

Ethics statement. Acquisition of this dataset was approved by Institutional Review Board at Oregon Health \& Science University. All procedures were performed in compliance with the Code of Ethics of the World Medical Association (Declaration of Helsinki). Written informed consent and assent were obtained from all youth and their parents/guardians, in accordance with the local Institutional Review Board regulations.

Participants and study design. Details of this study design have been previously published ${ }^{24,92-94}$. Briefly, we enrolled 34 adolescent males ages 15 to 18 years. Written informed consent and assent were obtained from all youth and their parents/guardians, in accordance with the local Institutional Review Board regulations. All youth were administered a modified version of the Youth Adolescent Activity Questionnaire (YAAQ) to assess exercise participation over the year. The sample consisted of both athletes and non-athletes. Briefly, the YAAQ asks about participation in various types of physical activity (e.g., basketball, soccer, track, weightlifting, baseball, etc.) throughout the year, as well as the number of hours per week spent doing each activity. Youth were enrolled if they met "high" or "low" fit criteria. High-fit was defined as engaged in an average of $\geq 10 \mathrm{~h}$ per week of regular organized aerobic physical activity across one or more seasons within the past year. Low-fit youth were defined as individuals who had participated in $\leq 1.5 \mathrm{~h}$ of highly aerobic physical activity per week over the past year. High-fit youth were asked to participate in the study during the season in which they were most physically active based on their YAAQ self-report (see Supplementary Table S3 for aerobic fitness characteristics of participants from YAAQ self-report). Of the 34 participants enrolled, 17 were high-fit and 17 were low-fit. Although participants were initially enrolled in the study based on these self-reports, previous analyses using this sample found $\mathrm{VO}_{2}$ peak $(\mathrm{ml} / \mathrm{kg} \mathrm{LBM} / \mathrm{min})$ was a stronger predictor than group membership in relation to hippocampal volumes $^{95}$. In addition, self-reports of aerobic training can be biased by perception ${ }^{96}$. Thus, the current study focused on objective measurement of $\mathrm{VO}_{2}$ peak as the primary independent variable of interest.

In designing the current study, we carefully considered and chose to limit various sample characteristics in order to reduce variability. For example, a number of intrinsic sex differences have been reported in aerobic fitness ability, overall physical fitness level, hippocampal volumetric, and virtual maze task differences ${ }^{97-103}$. As such, we begin to explore this question in the male population first, and specifically recruited one sex in order to reduce between sex variability within the study sample. Left handers were also excluded from the current study due to the demonstrated handedness (general handedness and sport-specific lateral preferences) on cerebral laterality during adolescence ${ }^{104-106}$. Additional exclusion criteria were a diagnosis of a DSM-IV psychiatric disorder, significant substance use ( $>10$ lifetime alcoholic drinks or 2 drinks/occasion, $>5$ uses of marijuana, any other drug use, or $>4$ cigarettes per day), reported history of psychotic disorders in biological parents, any major medical condition or significant head trauma, left-handedness ${ }^{107}$, or irremovable metal in the body. Eligible participants were asked to complete aerobic fitness testing, questionnaires, cognitive testing, and an MRI scan within a 1 -week period. Given acute effects of exercise on $\operatorname{cognition}{ }^{108,109}$, aerobic testing never preceded cognitive or MRI scanning assessments. To assess intellectual functioning, participants were administered the two-subtest version of the Weschler Abbreviated Scale of Intelligence ${ }^{110}$. Socioeconomic status information was gathered by administering the Hollingshead Index of Social Position questionnaire to parents ${ }^{111}$. Pubertal development 
during adolescence is a potential confound as physical exercise has been reported to delay pubertal maturation ${ }^{112}$. Thus, pubertal maturation was assessed for each subject using self-rating Pubertal Development Scale (PDS) ${ }^{113}$.

Aerobic fitness assessment. Aerobic fitness was assessed by measuring peak oxygen consumption using the Bruce Protocol wherein participants ran on a graded treadmill at a speed of $1.7 \mathrm{mph}$ and $10 \%$, with increases in speed and grade every 3 min until volitional exhaustion ${ }^{55}$. Individual fitness levels were measured using $\mathrm{VO}_{2}$ peak, which is a measure of the highest rate of an individual's body to transport and utilize oxygen during incremental exercise and is thought to be the gold standard of measurement for aerobic physical fitness ${ }^{56}$. Oxygen consumption was calculated using the exact same Vmax Series, V6200 Autobox computerized indirect calorimetry system for every participant. $\mathrm{VO}_{2}$ peak values were only considered valid if the participant had delivered maximal effort on a test, which can be defined as one of the following conditions ${ }^{56,96,114-118}$ : (1) heart rate reaching 200 beats or greater per minute ${ }^{96},(2)$ a respiratory exchange ratio greater or equal to $1: 0^{96}$, (3) or a plateau in oxygen consumption indicating a steady state despite an increased workload. These thresholds for a valid $\mathrm{VO}_{2}$ peak are based on previous findings in children and adolescents, which corroborate that maximum heart rate at $\mathrm{VO}_{2}$ peak is independent of age ${ }^{96,119-121}$, maturation ${ }^{96,119,122,123}$, and $\operatorname{sex}^{96,124-126}$ during this time of development. Furthermore, respiratory exchange ratios greater or equal to 1 following a progressive exercise test is an informative indicator of near maximal effort in adolescents ${ }^{96}$. Since body mass has been related to aerobic fitness performance and hippocampal volume, $\mathrm{VO}_{2}$ peak measurements were scaled by lean body mass (LBM) to calculate an objective measure of aerobic fitness as $\mathrm{ml} / \mathrm{kg} \mathrm{LBM} / \mathrm{min}^{127-132}$. During the adolescent period, boys experience an increase in LBM, which accounts for robust changes in $\mathrm{VO}_{2}$ peak seen with age ${ }^{133}$. Thus, LBM based $\mathrm{VO}_{2}$ peak in $\mathrm{ml} / \mathrm{kg} \mathrm{LBM} / \mathrm{min}$ was used in the current study to allow for a body mass independent measure of cardiopulmonary fitness ${ }^{134}$, and to reduce the possibility of body fat as a confounding variable.

While the intention of the study was to recruit both high and low-fit adolescents, in the current sample, all participants had $\mathrm{V} \mathrm{VO}_{2}$ peak $(\mathrm{ml} / \mathrm{kg} / \mathrm{min})$ in the top 50 th percentile for their age and sex ${ }^{90}$. Likely owing to the inclusion of both athletes and non-athletes in the current study, $47 \%$ of the sample fell within the top 95th percentile. Seventeen youth qualified as "low-fit" on the YAAQ but displayed a high $\mathrm{VO}_{2}$ peak group average of $67 \mathrm{ml} / \mathrm{kg} \mathrm{LBM} / \mathrm{min}$ (see Supplementary Table S3). The discrepancy between low self-report measures of fitness activity and high $\mathrm{VO}_{2}$ peak average values may be due to inherent perception biases when self-reporting aerobic training ${ }^{96}$. Thus, given that $\mathrm{VO}_{2}$ peak is considered to be the "gold standard" of a single objective measurement of aerobic fitness, and previously analyses using this data have shown that $\mathrm{LBM}$ based $\mathrm{VO}_{2}$ peak $(\mathrm{ml} / \mathrm{kg} \mathrm{LBM} /$ $\mathrm{min}$ ) was a stronger predictor than group membership in relation to hippocampal volumes ${ }^{95}$, the current study focused on $\mathrm{LBM}$ based $\mathrm{VO}_{2}$ peak as the primary independent variable of interest.

Spatial and verbal memory assessment. Details of the spatial memory paradigm have been previously published using this dataset ${ }^{24}$. Briefly, spatial learning and memory were assessed using a computerized virtual Morris Water Maze video game (vMWT) ${ }^{135}$ (Fig. 1a). The virtual environment of the task consisted of a pool of water with a ceiling, floor, walls, and four objects placed around the pool. The practice trial consisted of a hidden platform in a pool, and participants were instructed to find the hidden platform as fast as possible. Using a joystick, participants "swam" over to the platform, and it emerged from the water 10s later. Following the practice trial, the participant completed 6 learning trials in 6 different learning environments to locate a hidden platform in another position. Each learning trial began from a different start position, and total distance traveled from each start position to the hidden platform was calculated for every trial, as well as total distance traveled within in each 'quadrant' of the pool. While the participant searched for and found the hidden platform, the computer recorded the $\mathrm{x}, \mathrm{y}$ coordinate position approximately every $0.02 \mathrm{~s}$. Using this method, the computer calculated the total distance traveled in each quadrant of the pool, including the quadrant that the hidden platform was located in-known as the target quadrant. Percent distance traveled equaled the total distance traveled in the target quadrant divided by the total distance traveled across all quadrants. Percent distance traveled in the target quadrant was calculated for each of the 6 trials. Spatial learning across the 6 trials was measured as a metric of delta $(\delta)$; the change between percent distance traveled in the target quadrant between trial 1 and trial $6(\delta=$ trial 6 percent distance in target quadrant - trial 1 percent distance in target quadrant). 30 minutes after the completion of the learning trials on the vMWT, participants were asked to complete a spatial delay recall trial. The spatial delay recall trial was identical to the learning trials, but the hidden platform was removed. This was done to assess whether the participant remembered the location of the hidden platform that was identified during the previous 6 learning trials. Spatial delay recall was calculated as the percent distance traveled in the target quadrant within the first 30 s of the trial.

Verbal memory was assessed by the Rey Auditory Verbal Learning Test (RAVLT) ${ }^{136}$ (Fig. 1b). A list of 15 words, called list A, were read consecutively for five trials (Trials A1-A5), and participants verbally listed as many words as possible after each presentation. A second 15-word list (list B) was read to the participant and they were then asked to recall the list (Trial B1). Participants were then asked to immediately recall words from list A (Trial A6). After a 20-minute delay, participants were asked to recall the words from list A (Trial A7). A verbal learning score was calculated by summing the total number of words learned from list A over 5 trials, and final scores were $\mathrm{z}$-transformed. Delayed recall was calculated as the number words remembered from list A after a 20-min delay subtracted from words remembered from list A after the 5th trial (Trial A7-A1).

MRI acquisition and image analysis. Images were acquired on a 3.0T Siemens Magnetom Tim Trio system (Siemens Medical Solutions, Erlangen, Germany) with a twelve-channel head coil at OHSU's Advanced Imaging Research Center. Whole-brain, high-resolution structural anatomical images were acquired in the sagittal plane using a $\mathrm{T}_{1}$ weighted MPRAGE scanning sequence $\left(\mathrm{TI}=900 \mathrm{~ms}\right.$, Flip Angle $=10^{\circ}, \mathrm{TE}=3.58 \mathrm{~ms}$, 
$\mathrm{TR}=2300 \mathrm{~ms}$, acquisition matrix $=256 \times 240$, resolution $=1 \mathrm{~mm} \times 1 \mathrm{~mm} \times 1.1 \mathrm{~mm}$ ). Images were preprocessed using Freesurfer's recon-all (v5.3, http://surfer.nmr.mgh.harvard.edu) processing pipeline which includes: removing non brain tissue, tissue segmentations of grey matter (GM), white matter (WM), CSF boundaries, and Talairach transformation in standard MNI space ${ }^{137}$. Intracranial volume (ICV) was calculated using Functional Magnetic Resonance Imaging of the Brain (FMRIB)'s automated segmentation tool (FAST) v4.1 to account for individual variability in brain size ${ }^{138,139}$.

Hippocampal subfields were calculated using FreeSurfer's automated method in FreeSurfer v6.0 (beta version; http://surfer.nmr.mgh.harvard.edu $)^{26}$. Prior publications have listed the technical details of the processing procedure $^{140,141}$. This method provides hippocampal subfield volumetric measures that more closely align with histological measurements, compared to alternative automated segmentation algorithms and previous versions of the software ${ }^{26,137,142}$. Automated approaches have advantages over gold standard manual segmentation because of improved reliability ${ }^{142}$ and increase interstudy comparability. FreeSurfer segments the hippocampus in 12 regions of interest. These regions can be grouped as head, body, and tail (Fig. 2a). The head consists of the following subfields of interest: parasubiculum, presubiculum-head, subiculum-head, CA1-head, CA3-head, CA4-head, DG-head, molecular layer-head, and the hippocampal amygdala transition area (Fig. 2b). The body consists of the following subfields of interest: presubiculum-body, subiculum-body, CA1-body, CA3-body, CA4-body, DG-body, molecular layer body, and fimbria (Fig. 2c). Hippocampal images were created using Quantitative Imaging Toolkit (QIT) ${ }^{143}$.

Statistical analysis. Data were analyzed using RStudio Version 1.1.463 and the following packages: reghelper, r2glmm, nlme, dplyr, and tidyr. We used a strategic model building approach to examine how the independent variables (IV) of aerobic fitness (i.e. $\mathrm{VO}_{2}$ peak), virtual Morris Water Maze performance (learning and memory), and verbal memory performance (learning and memory) related to subfield volume. Covariates ICV and PDS score were included in the model to account for individual variability in brain size, and the impact of pubertal development on hippocampal size ${ }^{144-147}$. Given the high correlation of subfield volumes between and within hemispheres for any given individual, linear mixed effects models were used to examine if there was an association between the independent variable (i.e. aerobic fitness, spatial learning, etc.) and volume as a function of the hippocampal subfield ROIs, with fixed effects for hemisphere, ICV, PDS, and subject as a random effect.

Based on the literature, an a priori model building strategy was used to examine both the anterior-posterior axis of the hippocampus, as well as subfield volumes based on the IV of interest (Fig. 2). First, we examined a potential interaction between the IV (i.e. $\mathrm{VO}_{2}$ peak, spatial learning, verbal learning, etc.) and regional differences in volume along the longitudinal axis (head, body, tail ROIs) of the hippocampus (Fig. 1a). This initial model for the IV of $\mathrm{VO}_{2}$ peak was:

$$
\begin{aligned}
& \text { M1: } \text { Volume }_{i} \\
& \left.=b_{0}+b_{1} \text { VO2peak }_{i} * b_{2} \text { LongAxis(Head, Body, Tail }\right)_{i} \\
& \left.+b_{3} \text { Hemisphere (Left, Right }\right)_{i}+b_{4} I C V_{i}+b_{5} P D S_{i}+U_{i}+\varepsilon_{i}
\end{aligned}
$$

Based on this initial result, we then completed one of two follow-up analyses to probe subfield volumes of interest. If the interaction of the initial model was significant, suggesting volume differences along the longitudinal axis (head, body, tail), follow-up analyses examined volume differences of the subfields of interest (i.e. CA1, CA3, CA4, DG, presubiculum, subiculum, and parasubiculum) within the longitudinal axis region identified by the initial model (Fig. 2b). This follow-up model was:

$$
\begin{aligned}
& \text { M2: } \text { Volume }_{i} \\
& =b_{0}+b_{1} \text { VO2peak }_{i} * b_{2} \text { Head Specific Subfields(CA1, CA3, CA4, DG) } \\
& +b_{3} \text { Hemisphere }(\text { Left, Right })_{i}+b_{4} I C V_{i}+b_{5} P D S_{i}+U_{i}+\varepsilon_{i}
\end{aligned}
$$

Specifically, if there was no support for differences in volume along the longitudinal axis (i.e. interaction term for the longitudinal axis was not significant), then the subfields of interest (i.e. CA1, CA3, CA4, DG, presubiculum, subiculum, and parasubiculum) were examined for the entire length of the hippocampal formation (Fig. 2c). For each IV, subfields were chosen a priori based on literature derived from previous animal ${ }^{20,22}$ and human subfield-related studies ${ }^{58}$. Model fits were then examined using the F-values and $p$ values for the fixed effects via the anova.lme function. Given the number of regression analyses performed, Bonferroni corrections were applied to each group of tests per IV to reduce reporting Type I errors (2 primary models for aerobic fitness: $p<0.025 ; 4$ primary models for vMWT and RAVLT: $p<0.0125)$, whereas to correct for the number of post-hoc follow-up analyses of these models to investigate up to 7 ROIs included a Bonferroni correction of $p<0.007$. Together, this modeling strategy allowed for testing how aerobic fitness, spatial learning and memory, and verbal learning and memory relate to (1) volumetric differences along the anterior-posterior longitudinal axis of the hippocampus and (2) regional specificity of subfield volumes localized along this longitudinal axis. Finally, a mediation analysis outlined by Baron and Kinney ${ }^{59}$ was performed to test whether hippocampal subfield volumes would mediate the relationship between aerobic fitness and memory outcomes. All statistics reported are for the two-tailed test criterion.

\section{Data availability}

The datasets generated during and analyzed for the current study are available from the authors on reasonable request. 
Received: 11 November 2019; Accepted: 7 April 2021

Published online: 29 April 2021

\section{References}

1. Blair, S. N., LaMonte, M. J. \& Nichaman, M. Z. The evolution of physical activity recommendations: how much is enough? Am. J. Clin. Nutr. 79, 913S-920S (2004).

2. Pate, R. R., Long, B. J. \& Heath, G. Descriptive epidemiology of physical activity in adolescents. Pediatr. Exerc. Sci. 6, 434-447 (1994).

3. Troiano, R. P. et al. Physical activity in the United States measured by accelerometer. Med. Sci. Sports Exerc. 40, 181-188 (2008).

4. Organization, W. H. Prevalence of insufficient physical activity. Global Health Observatory (GHO) Data (2010).

5. Health, U. D. O. \& Services, H. in Healthy People 2000: National Health Promotion and Disease Prevention Objectives (US Government Printing Office, 1991).

6. Health, U. D. O. \& Services, H. Physical activity guidelines for Americans: be active, healthy, and happy! http://www.health.gov/ paguidelines/guidelines/default.aspx (2008).

7. Sawyer, S. M., Azzopardi, P. S., Wickremarathne, D. \& Patton, G. C. The age of adolescence. Lancet Child Adolesc. Health 2 , 223-228 (2018).

8. Andersen, S. L. Trajectories of brain development: point of vulnerability or window of opportunity? Neurosci. Biobehav. Rev. 27, 3-18 (2003).

9. Lenroot, R. K. \& Giedd, J. N. Brain development in children and adolescents: insights from anatomical magnetic resonance imaging. Neurosci. Biobehav. Rev. 30, 718-729 (2006).

10. Casey, B. J., Getz, S. \& Galvan, A. The adolescent brain. Dev. Rev. 28, 62-77 (2008).

11. Corbin, C. B., Pangrazi, R. P. \& Franks, B. D. Definitions: Health, fitness, and physical activity. President's Council on Physical Fitness and Sports Research Digest (2000).

12. Sibley, B. A. \& Etnier, J. L. The relationship between physical activity and cognition in children: a meta-analysis. Pediatr. Exerc. Sci. 15, 243-256 (2003).

13. Esteban-Cornejo, I., Tejero-Gonzalez, C. M., Sallis, J. F. \& Veiga, O. L. Physical activity and cognition in adolescents: a systematic review. J. Sci. Med. Sport 18, 534-539 (2015).

14. Herting, M. M. \& Chu, X. Exercise, cognition, and the adolescent brain. Birth Defects Res. 109, 1672-1679 (2017).

15. Biddle, S. J., Ciaccioni, S., Thomas, G. \& Vergeer, I. Physical activity and mental health in children and adolescents: an updated review of reviews and an analysis of causality. Psychol. Sport Exerc. 42, 146-155 (2019).

16. Poitras, V. J. et al. Systematic review of the relationships between objectively measured physical activity and health indicators in school-aged children and youth. Appl. Physiol. Nutr. Metab. 41, S197-S239 (2016).

17. Ashdown-Franks, G. et al. Exercise as medicine for mental and substance use disorders: a meta-review of the benefits for neuropsychiatric and cognitive outcomes. Sports Med. 50, 1-20 (2020).

18. Belcher, B. R. et al. The roles of physical activity, exercise, and fitness in promoting resilience during adolescence: effects on mental well-being and brain development. Biol. Psychiatry Cogn. Neurosci. Neuroimaging 6, 225-237 (2020).

19. van Praag, H., Christie, B. R., Sejnowski, T. J. \& Gage, F. H. Running enhances neurogenesis, learning, and long-term potentiation in mice. Proc. Natl. Acad. Sci. U. S. A. 96, 13427-13431 (1999).

20. Uysal, N. et al. The effects of regular aerobic exercise in adolescent period on hippocampal neuron density, apoptosis and spatial memory. Neurosci. Lett. 383, 241-245. https://doi.org/10.1016/j.neulet.2005.04.054 (2005).

21. Uda, M., Ishido, M., Kami, K. \& Masuhara, M. Effects of chronic treadmill running on neurogenesis in the dentate gyrus of the hippocampus of adult rat. Brain Res. 1104, 64-72 (2006).

22. Saur, L. et al. Physical exercise increases GFAP expression and induces morphological changes in hippocampal astrocytes. Brain Struct. Funct. 219, 293-302. https://doi.org/10.1007/s00429-012-0500-8 (2014).

23. Brockett, A. T., LaMarca, E. A. \& Gould, E. Physical exercise enhances cognitive flexibility as well as astrocytic and synaptic markers in the medial prefrontal cortex. PLoS ONE 10, e0124859. https://doi.org/10.1371/journal.pone.0124859 (2015).

24. Herting, M. M. \& Nagel, B. J. Aerobic fitness relates to learning on a virtual Morris water task and hippocampal volume in adolescents. Behav. Brain Res. 233, 517-525 (2012).

25. Stillman, C. M., Esteban-Cornejo, I., Brown, B., Bender, C. M. \& Erickson, K. I. Effects of exercise on brain and cognition across age groups and health states. Trends Neurosci. 43, 533-543 (2020).

26. Iglesias, J. E. et al. A computational atlas of the hippocampal formation using ex vivo, ultra-high resolution MRI: application to adaptive segmentation of in vivo MRI. Neuroimage 115, 117-137 (2015).

27. Chaddock, L. et al. A neuroimaging investigation of the association between aerobic fitness, hippocampal volume, and memory performance in preadolescent children. Brain Res. 1358, 172-183 (2010).

28. Gorham, L. S., Jernigan, T., Hudziak, J. \& Barch, D. M. Involvement in sports, hippocampal volume, and depressive symptoms in children. Biol. Psychiatry Cogn. Neurosci. Neuroimaging 4, 484-492 (2019).

29. Erickson, K. I. et al. Aerobic fitness is associated with hippocampal volume in elderly humans. Hippocampus 19, 1030-1039 (2009).

30. Erickson, K. I. et al. Exercise training increases size of hippocampus and improves memory. Proc. Natl. Acad. Sci. U. S. A. 108, 3017-3022. https://doi.org/10.1073/pnas.1015950108 (2011).

31. Thomas, A. G. et al. Multi-modal characterization of rapid anterior hippocampal volume increase associated with aerobic exercise. Neuroimage 131, 162-170 (2016).

32. Nauer, R. K., Dunne, M. F., Stern, C. E., Storer, T. W. \& Schon, K. Improving fitness increases dentate gyrus/CA3 volume in the hippocampal head and enhances memory in young adults. Hippocampus 30, 488-504 (2019).

33. Maass, A. et al. Vascular hippocampal plasticity after aerobic exercise in older adults. Mol. Psychiatry 20, 585 (2015).

34. Pereira, A. C. et al. An in vivo correlate of exercise-induced neurogenesis in the adult dentate gyrus. Proc. Natl. Acad. Sci. 104, 5638-5643 (2007).

35. Stillman, C. M. et al. Cardiorespiratory fitness is associated with enhanced hippocampal functional connectivity in healthy young adults. Hippocampus 28, 239-247 (2018).

36. Eriksson, P. S. et al. Neurogenesis in the adult human hippocampus. Nat. Med. 4, 1313-1317 (1998).

37. Kuhn, H. G., Dickinson-Anson, H. \& Gage, F. H. Neurogenesis in the dentate gyrus of the adult rat: age-related decrease of neuronal progenitor proliferation. J. Neurosci. 16, 2027-2033 (1996).

38. Li, G., Fang, L., Fernández, G. \& Pleasure, S. J. The ventral hippocampus is the embryonic origin for adult neural stem cells in the dentate gyrus. Neuron 78, 658-672 (2013).

39. Strange, B. A., Witter, M. P., Lein, E. S. \& Moser, E. I. Functional organization of the hippocampal longitudinal axis. Nat. Rev. Neurosci. 15, 655 (2014).

40. Zeidman, P. \& Maguire, E. A. Anterior hippocampus: the anatomy of perception, imagination and episodic memory. Nat. Rev. Neurosci. 17, 173-182 (2016).

41. Hackert, V. et al. Hippocampal head size associated with verbal memory performance in nondemented elderly. Neuroimage 17, 1365-1372 (2002). 
42. Den Ouden, L. et al. The influence of aerobic exercise on hippocampal integrity and function: preliminary findings of a multimodal imaging analysis. Brain Plast. 4, 211-216 (2018).

43. Broadbent, N. J., Squire, L. R. \& Clark, R. E. Spatial memory, recognition memory, and the hippocampus. Proc. Natl. Acad. Sci. 101, 14515-14520 (2004).

44. Gilbert, P. E., Kesner, R. P. \& Lee, I. Dissociating hippocampal subregions: a double dissociation between dentate gyrus and CA1. Hippocampus 11, 626-636 (2001).

45. Yassa, M. A. \& Stark, C. E. Pattern separation in the hippocampus. Trends Neurosci. 34, 515-525 (2011).

46. Lee, I. \& Kesner, R. P. Differential roles of dorsal hippocampal subregions in spatial working memory with short versus intermediate delay. Behav. Neurosci. 117, 1044 (2003).

47. Nakazawa, K. et al. Hippocampal CA3 NMDA receptors are crucial for memory acquisition of one-time experience. Neuron 38, 305-315 (2003).

48. Ainge, J. A., Tamosiunaite, M., Woergoetter, F. \& Dudchenko, P. A. Hippocampal CA1 place cells encode intended destination on a maze with multiple choice points. J. Neurosci. 27, 9769-9779 (2007).

49. Bartsch, T. et al. Focal lesions of human hippocampal CA1 neurons in transient global amnesia impair place memory. Science 328, 1412-1415 (2010).

50. Wierenga, L. et al. Typical development of basal ganglia, hippocampus, amygdala and cerebellum from age 7 to 24 . Neuroimage 96, 67-72 (2014).

51. Narvacan, K., Treit, S., Camicioli, R., Martin, W. \& Beaulieu, C. Evolution of deep gray matter volume across the human lifespan. Hum. Brain Mapp. 38, 3771-3790 (2017).

52. Tamnes, C. K. et al. Regional hippocampal volumes and development predict learning and memory. Dev. Neurosci. 36, 161-174 (2014).

53. Kim, Y.-P. et al. Age-dependence of the effect of treadmill exercise on cell proliferation in the dentate gyrus of rats. Neurosci. Lett. 355, 152-154 (2004).

54. Suthana, N. A., Ekstrom, A. D., Moshirvaziri, S., Knowlton, B. \& Bookheimer, S. Y. Human hippocampal CA1 involvement during allocentric encoding of spatial information. J. Neurosci. 29, 10512-10519 (2009).

55. Bruce, R. A., Kusumi, F. \& Hosmer, D. Maximal oxygen intake and nomographic assessment of functional aerobic impairment in cardiovascular disease. Am. Heart J. 85, 546-562 (1973).

56. Armstrong, N. \& Welsman, J. R. Aerobic fitness: what are we measuring? In Pediatric Fitness Vol. 50 (eds Tomkinson, G. R. \& Olds, T. S.) 5-25 (Karger Publishers, 2007).

57. Nowak, N. T. \& Moffat, S. D. The relationship between second to fourth digit ratio, spatial cognition, and virtual navigation. Arch. Sex. Behav. 40, 575-585 (2011).

58. Van Strien, N., Cappaert, N. \& Witter, M. The anatomy of memory: an interactive overview of the parahippocampal-hippocampal network. Nat. Rev. Neurosci. 10, 272 (2009).

59. Baron, R. M. \& Kenny, D. A. The moderator-mediator variable distinction in social psychological research: conceptual, strategic, and statistical considerations. J. Pers. Soc. Psychol. 51, 1173 (1986).

60. Duvernoy, H. M. The Human Hippocampus: An Atlas of Applied Anatomy (JF Bergmann-Verlag, 2013)

61. Piatti, V. C. et al. The timing for neuronal maturation in the adult hippocampus is modulated by local network activity. J. Neurosci. 31, 7715-7728 (2011).

62. Tanti, A. \& Belzung, C. Neurogenesis along the septo-temporal axis of the hippocampus: are depression and the action of antidepressants region-specific? Neuroscience 252, 234-252 (2013).

63. Carmichael, O. et al. Localized hippocampus measures are associated with Alzheimer pathology and cognition independent of total hippocampal volume. Neurobiol. Aging 33(1124), e1131-1124.e1141 (2012).

64. De Flores, R., La Joie, R. \& Chételat, G. Structural imaging of hippocampal subfields in healthy aging and Alzheimer's disease. Neuroscience 309, 29-50 (2015).

65. Sahay, A. \& Hen, R. Adult hippocampal neurogenesis in depression. Nat. Neurosci. 10, 1110-1115 (2007).

66. DeKraker, J., Lau, J. C., Ferko, K. M., Khan, A. R. \& Köhler, S. Hippocampal subfields revealed through unfolding and unsupervised clustering of laminar and morphological features in 3D BigBrain. Neuroimage 206, 116328 (2020).

67. Amaral, D. G., Insausti, R. \& Cowan, W. The commissural connections of the monkey hippocampal formation. J. Comp. Neurol. 224, 307-336 (1984).

68. Rosene, D. L. \& Van Hoesen, G. W. The hippocampal formation of the primate brain: a review of some comparative aspects of cytoarchitecture and connections. In Cerebral Cortex (eds Jones, E. G. \& Peters, A.) 345-456 (Springer, 1987).

69. Broadhouse, K. M. et al. Hippocampal plasticity underpins long-term cognitive gains from resistance exercise in MCI. NeuroImage Clin. 25, 102182 (2020).

70. Vivar, C. \& van Praag, H. Running changes the brain: the long and the short of it. Physiology 32, 410-424 (2017).

71. Stranahan, A. M., Khalil, D. \& Gould, E. Running induces widespread structural alterations in the hippocampus and entorhinal cortex. Hippocampus 17, 1017-1022 (2007).

72. Neeper, S. A., Góauctemez-Pinilla, F., Choi, J. \& Cotman, C. Exercise and brain neurotrophins. Nature 373, 109-109 (1995).

73. Oladehin, A. \& Waters, R. S. Location and distribution of Fos protein expression in rat hippocampus following acute moderate aerobic exercise. Exp. Brain Res. 137, 26-35 (2001).

74. Kang, H. \& Schuman, E. M. Long-lasting neurotrophin-induced enhancement of synaptic transmission in the adult hippocampus. Science 267, 1658-1662 (1995).

75. Maguire, E. A. et al. Navigation-related structural change in the hippocampi of taxi drivers. Proc. Natl. Acad. Sci. 97, 4398-4403 (2000).

76. Hartley, T., Maguire, E. A., Spiers, H. J. \& Burgess, N. The well-worn route and the path less traveled: distinct neural bases of route following and wayfinding in humans. Neuron 37, 877-888 (2003).

77. Ekstrom, A. D., Copara, M. S., Isham, E. A., Wang, W.-C. \& Yonelinas, A. P. Dissociable networks involved in spatial and temporal order source retrieval. Neuroimage 56, 1803-1813 (2011).

78. Morgan, L. K., MacEvoy, S. P., Aguirre, G. K. \& Epstein, R. A. Distances between real-world locations are represented in the human hippocampus. J. Neurosci. 31, 1238-1245 (2011).

79. O'Keefe, J. \& Dostrovsky, J. The hippocampus as a spatial map: preliminary evidence from unit activity in the freely-moving rat. Brain Res. 34, 171-175 (1971).

80. Chen, G., King, J. A., Burgess, N. \& O’Keefe, J. How vision and movement combine in the hippocampal place code. Proc. Natl. Acad. Sci. 110, 378-383 (2013).

81. Aghajan, Z. M. et al. Impaired spatial selectivity and intact phase precession in two-dimensional virtual reality. Nat. Neurosci. 18, $121(2015)$

82. Strange, B., Otten, L., Josephs, O., Rugg, M. \& Dolan, R. J. Dissociable human perirhinal, hippocampal, and parahippocampal roles during verbal encoding. J. Neurosci. 22, 523-528 (2002).

83. Rosazza, C. et al. Engagement of the medial temporal lobe in verbal and nonverbal memory: assessment with functional MR imaging in healthy subjects. Am. J. Neuroradiol. 30, 1134-1141 (2009).

84. Creer, D. J., Romberg, C., Saksida, L. M., van Praag, H. \& Bussey, T. J. Running enhances spatial pattern separation in mice. Proc. Natl. Acad. Sci. 107, 2367-2372 (2010). 
85. Tamnes, C. K., Bos, M. G., van de Kamp, F. C., Peters, S. \& Crone, E. A. Longitudinal development of hippocampal subregions from childhood to adulthood. Dev. Cogn. Neurosci. 30, 212-222 (2018).

86. Balvin, N. \& Banati, P. R. The Adolescent Brain: A second window of opportunity - A compendium. https://www.unicef-irc.org/ publications/933-the-adolescent-brain-a-second-window-of-opportunity-a-compendium.html. (MiscellaneaUNICEF Office of Research-Innocenti, Florence, 2017)

87. Kandel, E. R. et al. Principles of Neural Science Vol. 4 (McGraw-Hill, 2000).

88. Chaddock-Heyman, L. et al. Aerobic fitness is associated with greater hippocampal cerebral blood flow in children. Dev. Cogn. Neurosci. 20, 52-58 (2016)

89. Wenger, E. et al. Comparing manual and automatic segmentation of hippocampal volumes: reliability and validity issues in younger and older brains. Hum. Brain Mapp. 35, 4236-4248 (2014).

90. Eisenmann, J. C., Laurson, K. R. \& Welk, G. J. Aerobic fitness percentiles for US adolescents. Am. J. Prev. Med. 41, S106-S110 (2011).

91. Serra, F. T. et al. Early exercise induces long-lasting morphological changes in cortical and hippocampal neurons throughout of a sedentary period of rats. Sci. Rep. 9, 1-11 (2019).

92. Herting, M. M. \& Nagel, B. J. Differences in brain activity during a verbal associative memory encoding task in high-and low-fit adolescents. J. Cogn. Neurosci. 25, 595-612 (2013).

93. Herting, M. M., Colby, J. B., Sowell, E. R. \& Nagel, B. J. White matter connectivity and aerobic fitness in male adolescents. Dev. Cogn. Neurosci. 7, 65-75. https://doi.org/10.1016/j.dcn.2013.11.003 (2014).

94. Herting, M. M., Keenan, M. F. \& Nagel, B. J. Aerobic fitness linked to cortical brain development in adolescent males: preliminary findings suggest a possible role of BDNF genotype. Front. Hum. Neurosci. 10, 327. https://doi.org/10.3389/fnhum.2016.00327 (2016).

95. Herting, M. M. The Influence of Aerobic Exercise on Hippocampal Structure and Function in Male Adolescents (Oregon Health \& Science University, 2012).

96. Armstrong, N. \& Van Mechelen, W. Paediatric Exercise Science and Medicine (Oxford University Press, 2008).

97. Riddoch, C. J. et al. Physical activity levels and patterns of 9-and 15-yr-old European children. Med. Sci. Sports Exerc. 36, 86-92 (2004).

98. Krahenbuhl, G. S., Skinner, J. S. \& Kohrt, W. M. Developmental aspects of maximal aerobic power in children. Exerc. Sport Sci. Rev. 13, 503-538 (1985)

99. Gogtay, N. et al. Dynamic mapping of normal human hippocampal development. Hippocampus 16, 664-672 (2006).

100. Giedd, J. N. et al. Quantitative MRI of the temporal lobe, amygdala, and hippocampus in normal human development: ages 4-18 years. J. Comp. Neurol. 366, 223-230 (1996).

101. Newhouse, P., Newhouse, C. \& Astur, R. S. Sex differences in visual-spatial learning using a virtual water maze in pre-pubertal children. Behav. Brain Res. 183, 1-7 (2007).

102. Lövdén, M. et al. Quantitative and qualitative sex differences in spatial navigation. Scand. J. Psychol. 48, 353-358 (2007)

103. Astur, R. S., Tropp, J., Sava, S., Constable, R. T. \& Markus, E. J. Sex differences and correlations in a virtual Morris water task, a virtual radial arm maze, and mental rotation. Behav. Brain Res. 151, 103-115 (2004).

104. Lux, S. et al. Crossed cerebral lateralization for verbal and visuo-spatial function in a pair of handedness discordant monozygotic twins: MRI and fMRI brain imaging. J. Anat. 212, 235-248 (2008).

105. Loffing, F., Sölter, F. \& Hagemann, N. Left preference for sport tasks does not necessarily indicate left-handedness: sport-specific lateral preferences, relationship with handedness and implications for laterality research in behavioural sciences. PLoS ONE $\mathbf{9}$, e105800 (2014).

106. Nagel, B. J., Herting, M. M., Maxwell, E. C., Bruno, R. \& Fair, D. Hemispheric lateralization of verbal and spatial working memory during adolescence. Brain Cogn. 82, 58-68 (2013).

107. Oldfield, R. C. The assessment and analysis of handedness: the Edinburgh inventory. Neuropsychologia 9, 97-113 (1971).

108. Brisswalter, J., Collardeau, M. \& René, A. Effects of acute physical exercise characteristics on cognitive performance. Sports Med. 32, 555-566 (2002).

109. Chang, Y.-K., Labban, J. D., Gapin, J. I. \& Etnier, J. L. The effects of acute exercise on cognitive performance: a meta-analysis. Brain Res. 1453, 87-101 (2012).

110. Wechsler, D. WASI-II: Wechsler Abbreviated Scale of Intelligence (PsychCorp, 2011).

111. Hollingshead, A. D. B. Four factor index of social status. (Yale University, New Haven, CT, 1975).

112. Georgopoulos, N. A. et al. The influence of intensive physical training on growth and pubertal development in athletes. Ann. N. Y. Acad. Sci. 1205, 39-44. https://doi.org/10.1111/j.1749-6632.2010.05677.x (2010).

113. Petersen, A. C., Crockett, L., Richards, M. \& Boxer, A. A self-report measure of pubertal status: reliability, validity, and initial norms. J. Youth Adolesc. 17, 117-133 (1988).

114. van der Heijden, G.-J., Sauer, P. J. \& Sunehag, A. L. Twelve weeks of moderate aerobic exercise without dietary intervention or weight loss does not affect 24-h energy expenditure in lean and obese adolescents. Am. J. Clin. Nutr. 91, 589-596 (2010).

115. Treuth, M. S. et al. Metabolic adaptation to high-fat and high-carbohydrate diets in children and adolescents. Am. J. Clin. Nutr. 77, 479-489 (2003).

116. Leger, L. Aerobic performance. Meas. Pediatr. Exerc. Sci. 5, 183-223 (1996).

117. Armstrong, N., Welsman, J. \& Winsley, R. Is peak $\mathrm{VO}_{2}$ a maximal index of children's aerobic fitness? Int. J. Sports Med. 17, 356-359 (1996).

118. Rowland, T. W. Does peak $\mathrm{VO}_{2}$ reflect $\mathrm{VO}_{2 \max }$ in children?: evidence from supramaximal testing. Med. Sci. Sports Exerc. 25, 689-693 (1993).

119. Armstrong, N., Williams, J., Balding, J., Gentle, P. \& Kirby, B. The peak oxygen uptake of British children with reference to age, sex and sexual maturity. Eur. J. Appl. Physiol. 62, 369-375 (1991).

120. Bailey, D., Ross, W., Mirwald, R. \& Weese, C. Size dissociation of maximal aerobic power during growth in boys. In Pediatric Work Physiology Vol. 11 (eds Hebbelinck, M. \& Borms, J.) 140-151 (Karger Publishers, 1978).

121. Bale, P. Pre-and post-adolescents' physiological response to exercise. Br. J. Sports Med. 15, 246-249 (1981).

122. Armstrong, N., Welsman, J. R. \& Kirby, B. J. Peak oxygen uptake and maturation in 12-yr olds. Med. Sci. Sports Exerc. 30, 165-169 (1998).

123. Armstrong, N. \& Welsman, J. Peak oxygen uptake in relation to growth and maturation in 11-to 17-year-old humans. Eur. J. Appl. Physiol. 85, 546-551 (2001).

124. Armstrong, N., Kirby, B., McManus, A. \& Welsman, J. Aerobic fitness of prepubescent children. Ann. Hum. Biol. 22, 427-441 (1995).

125. Andersen, K. L., Seliger, V., Rutenfranz, J. \& Mocellin, R. Physical performance capacity of children in Norway. Eur. J. Appl. Physiol. 33, 177-195 (1974).

126. Vinet, A. et al. Influence of body composition, hemoglobin concentration, and cardiac size and function of gender differences in maximal oxygen uptake in prepubertal children. Chest 124, 1494-1499 (2003).

127. Dencker, M., Bugge, A., Hermansen, B., Froberg, K. \& Andersen, L. B. Aerobic fitness in prepubertal children according to level of body fat. Acta Paediatr. 99, 1854-1860 (2010). 
128. Hashimoto, T. et al. Increased posterior hippocampal volumes in children with lower increase in body mass index: a 3-year longitudinal MRI study. Dev. Neurosci. 37, 153-160 (2015).

129. Armstrong, N. \& Welsman, J. Development of peak oxygen uptake from 11 to 16 years determined using both treadmill and cycle ergometry. Eur. J. Appl. Physiol. 119, 801-812 (2019).

130. Graves, L. et al. Scaling of peak oxygen uptake in children: a comparison of three body size index models. Med. Sci. Sports Exerc. 45, 2341-2345 (2013).

131. Hunt, B. E. et al. Role of central circulatory factors in the fat-free mass-maximal aerobic capacity relation across age. Am. J. Physiol. Heart Circ. Physiol. 275, H1178-H1182 (1998).

132. Lolli, L., Batterham, A. M., Weston, K. L. \& Atkinson, G. Size exponents for scaling maximal oxygen uptake in over 6500 humans: a systematic review and meta-analysis. Sports Med. 47, 1405-1419 (2017).

133. Armstrong, N. \& Van Mechelen, W. Oxford Textbook of Children's Sport and Exercise Medicine (Oxford University Press, 2017).

134. Krachler, B. et al. Cardiopulmonary fitness is a function of lean mass, not total body weight: the DR's EXTRA study. Eur. J. Prev. Cardiol. 22, 1171-1179 (2015).

135. Connor, A. J. et al. An integrated approach to quantitative modelling in angiogenesis research. J. R. Soc. Interface 12, 0546. https://doi.org/10.1098/rsif.2015.0546 (2015).

136. Rey, A. L’examen clinique en psychologie. p. 222 (Presses universitaires de France, Paris, France, 1964).

137. Fischl, B. et al. Whole brain segmentation: automated labeling of neuroanatomical structures in the human brain. Neuron 33, 341-355 (2002).

138. Zhang, Y., Brady, M. \& Smith, S. Segmentation of brain MR images through a hidden Markov random field model and the expectation-maximization algorithm. IEEE Trans. Med. Imaging 20, 45-57 (2001).

139. Smith, S. M. et al. Advances in functional and structural MR image analysis and implementation as FSL. Neuroimage 23, S208S219 (2004).

140. Dale, A. M., Fischl, B. \& Sereno, M. I. Cortical surface-based analysis: I. Segmentation and surface reconstruction. Neuroimage 9, 179-194 (1999)

141. Fischl, B. et al. Sequence-independent segmentation of magnetic resonance images. Neuroimage 23, S69-S84 (2004).

142. Morey, R. A. et al. Scan-rescan reliability of subcortical brain volumes derived from automated segmentation. Hum. Brain Mapp. 31, 1751-1762 (2010).

143. Cabeen, R., Laidlaw, D. \& Toga, A. In Proceedings of the International Society for Magnetic Resonance in Medicine (ISMRM).

144. Buckner, R. L. et al. A unified approach for morphometric and functional data analysis in young, old, and demented adults using automated atlas-based head size normalization: reliability and validation against manual measurement of total intracranial volume. Neuroimage 23, 724-738 (2004).

145. Peper, J., Pol, H. H., Crone, E. \& Van Honk, J. Sex steroids and brain structure in pubertal boys and girls: a mini-review of neuroimaging studies. Neuroscience 191, 28-37 (2011).

146. Bramen, J. E. et al. Puberty influences medial temporal lobe and cortical gray matter maturation differently in boys than girls matched for sexual maturity. Cereb. Cortex 21, 636-646 (2010).

147. Herting, M. M., Maxwell, E. C., Irvine, C. \& Nagel, B. J. The impact of sex, puberty, and hormones on white matter microstructure in adolescents. Cereb. Cortex 22, 1979-1992 (2011).

\section{Acknowledgements}

This research was supported by the National Institute of Alcohol Abuse and Addiction Grant (F31AA019866; R01 AA017664), the National Institute of Neurological Disorders and Stroke (K08NS052147), the National Institute of Mental Health (K01MH108761), and the Rose Hill Foundation. Thank you to Dr. Elliot for her help with aerobic fitness testing, and to Dr. Scott Moffat for sharing his virtual spatial navigation task with us. We would also like to thank Dr. Hedyeh Ahmadi for her statistical advice during the review process.

\section{Author contributions}

M.M.H. and B.J.N. were responsible for study conception, design, and data acquisition. S.P. and M.M.H. conducted data analyses. S.P. wrote the manuscript, and all authors (S.P., M.M.H., B.J.N.) contributed to interpretation of the data, drafting, and revision of the intellectual content.

\section{Competing interests}

The authors declare no competing interests.

\section{Additional information}

Supplementary Information The online version contains supplementary material available at https://doi.org/ 10.1038/s41598-021-88452-9.

Correspondence and requests for materials should be addressed to M.M.H.

Reprints and permissions information is available at www.nature.com/reprints.

Publisher's note Springer Nature remains neutral with regard to jurisdictional claims in published maps and institutional affiliations.

(c) Open Access This article is licensed under a Creative Commons Attribution 4.0 International License, which permits use, sharing, adaptation, distribution and reproduction in any medium or format, as long as you give appropriate credit to the original author(s) and the source, provide a link to the Creative Commons licence, and indicate if changes were made. The images or other third party material in this article are included in the article's Creative Commons licence, unless indicated otherwise in a credit line to the material. If material is not included in the article's Creative Commons licence and your intended use is not permitted by statutory regulation or exceeds the permitted use, you will need to obtain permission directly from the copyright holder. To view a copy of this licence, visit http://creativecommons.org/licenses/by/4.0/.

(c) The Author(s) 2021 